\title{
A 14-year-old boy with Isolated Tuberculous Orchitis
}

\author{
Gurubacharya RL ${ }^{1}$, Gurubacharya $\mathbf{S M}^{2}$ \\ ${ }^{1}$ Dr Rajesh Lal Gurubacharya.MBBS. MD Pediatrician. Dr Simmi Misra Gurubacharya. MBBS. MD. Pediatrician.
}

Address for Correspondence: Dr. Rajesh Lal Gurubacharya, E-mail: rajesh_pul@hotmail.com

\begin{abstract}
The genitourinary tract is the most common extrapulmonary site affected by tuberculosis ${ }^{1}$. The male genital organs are involved in more than $50 \%$ of patients $^{2}$. The epididymis is the commonest structure to be involved, followed by the seminal vesicles, prostate, testis, and the vas deferens ${ }^{3}$. An isolated tuberculous orchitis without epididymal involvement is rare. This case report describes extra pulmonary tuberculosis with exclusively testicular presentation. The confirmatory diagnosis of which was made by FNAC of the testis. It provides a successful diagnosis, thereby preventing unnecessary orchidectomy.
\end{abstract}

Key words: genitourinary tuberculosis, testis, USG, FNAC

\section{Introduction}

The incidence of tuberculosis (TB) is increasing worldwide, with more than $20 \%$ of cases exhibiting extrapulmonary manifestations ${ }^{4}$. The genitourinary tract is the most common site of extrapulmonary TB. Testicular TB, although rare, may be the initial location of infection and may cause infertility. The diagnosis depends on culture of an organism. However, FNAC is a useful first choice of investigation ${ }^{5}$. Treatment for TB remains the combination of three or four anti-TB drugs for 8 to 10 months. Genitourinary TB remains relatively rare in Nepal and requires a high index of suspicion to make the diagnosis.

\section{Case Report}

A 14-year-old boy presented with painless unilateral scrotal enlargement of the right side along with two extra testicular masses on the same side for four months duration. No history of fever, cough, weight loss, anorexia or recent trauma could be elicited. There was no history of tubercular contact. His immunization was complete according to EPI schedule. On physical examination, boy was of average built. His height, weight and head circumference were within normal limits. Pulse rate, respiratory rate, temperature and BP were normal. The hernial orifices were intact. Rest of the general examination was normal. Systemic examination revealed no abnormalities.

On local examination, testis was found to be of orange-sized, firm to hard in consistency without any tenderness. Examination revealed $3 \times 2 \mathrm{~cm}$ extra testicular hard mass and arising from the upper and lower pole of right testis. The mass was non-tender and fixed to the overlying skin. Transillumination test of the right scrotal contents was negative. The spermatic cord was normal with intact sensations. The left testis and both epididymis were normal. Abdominal examination was normal and no nodes were palpable in the inguinal region. No free fluid was seen on either side.

Hemogram was normal. Urine examination was normal. Chest X-ray showed left pleural thickening and right pleural capping. Serum beta-hCG was within normal limit (normal $<0.5 \mathrm{mIU} / \mathrm{ml}$ ). To exclude a diagnosis of tuberculosis, Mantoux test was performed and was found to be $20 \times 20 \mathrm{~mm}$ at 72 hour. HIV was also negative.

USG of the scrotum revealed approximately $3.9 \times 3.1 \times 2.5 \mathrm{~cm}$ size complex hypoechoic mass noted in caudal and posterior aspect of the right testis abutting the tail of the epididymis (Figure 1). The extra testicular mass shows solid component in cranial aspect (Figure 2) and cystic component in caudal aspect (Figure 3) with particulated fluid within it. Another complex, predominantly cystic area seen in scrotal wall in the cranial aspect measuring approximately $3.1 \mathrm{~cm}$ in size (Figure 4).However, testis is normal in size, outline with parenchymal echo texture and echogenecity. Normal blood flow is seen in it. No space occupying lesion is seen within the testis. No dilated blood vessels and calcification were seen. Small free fluid is seen in tunica vaginalis. These features were suggestive of chronic 
granulomatous inflammation, probably of tuberculous etiology. However, the left testis was normal. Abdominal USG showed normal kidneys.

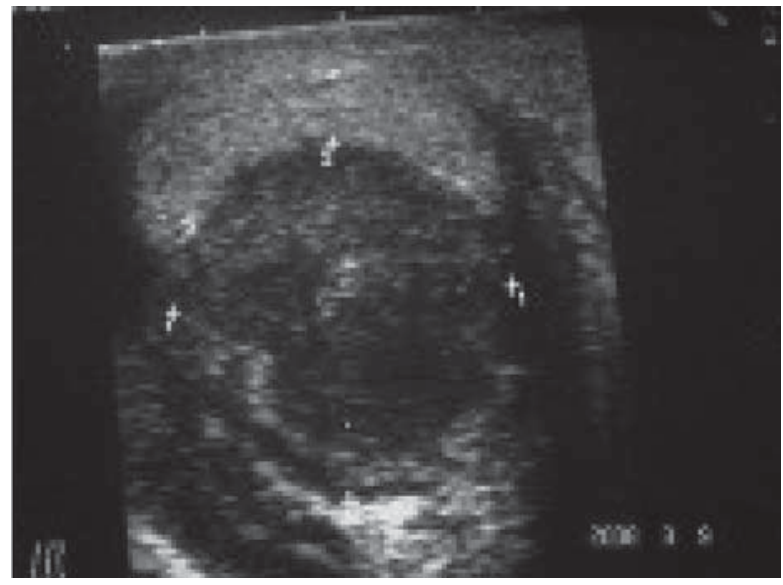

Fig. 1: Showing Hypoechoic Mass.

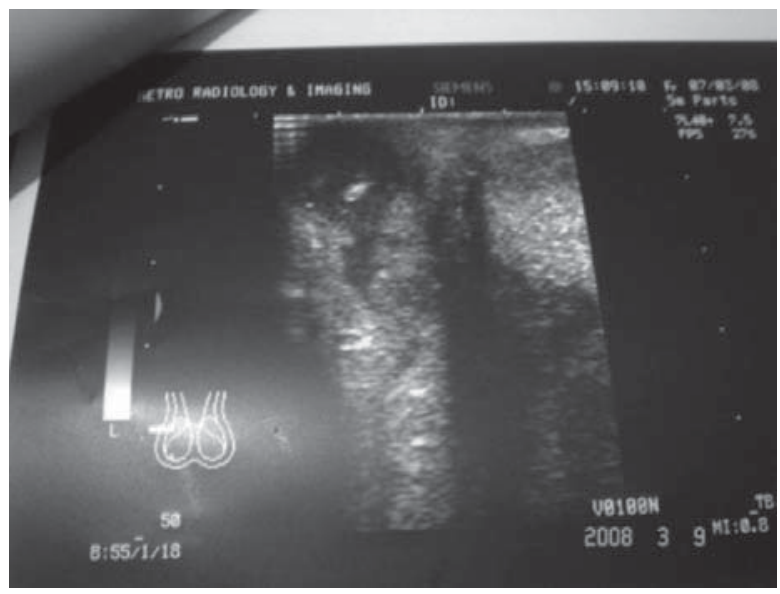

Fig. 2: Showing Solid Component in Cranial Aspect.

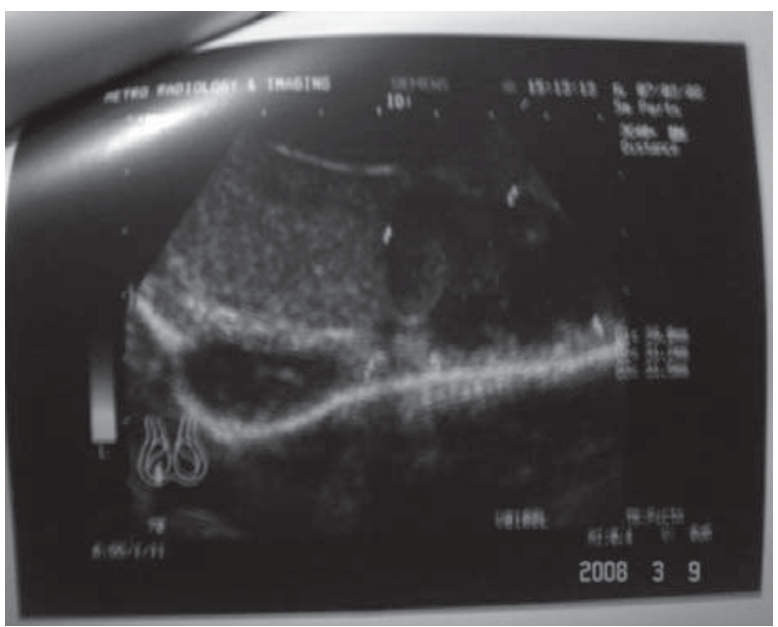

Fig. 3: Showing Cystic Component in Caudal Aspect.

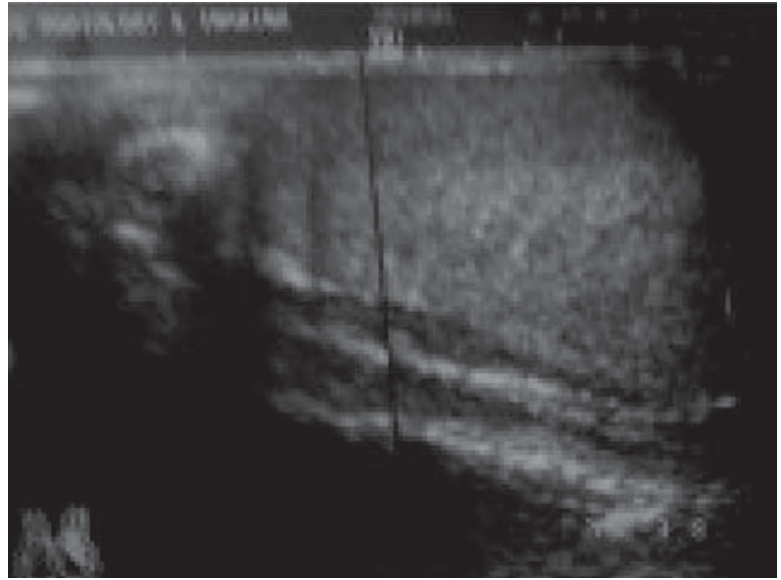

Fig. 4: Showing Cystic Area in Scrotal Wall.

Fine needle aspiration from the lesion was done and histopathology revealed a paratesticular lesion with large areas of necrosis, multiple epitheloid and giant cell granulomas. The granulomas consisted of epithelioid cells and Langhan's type giant cells with lymphocytic infiltration consistent with tuberculosis (Figure 5). The epididymis were found to be uninvolved. However, Z$\mathrm{N}$ staining and culture-sensitivity were negative.

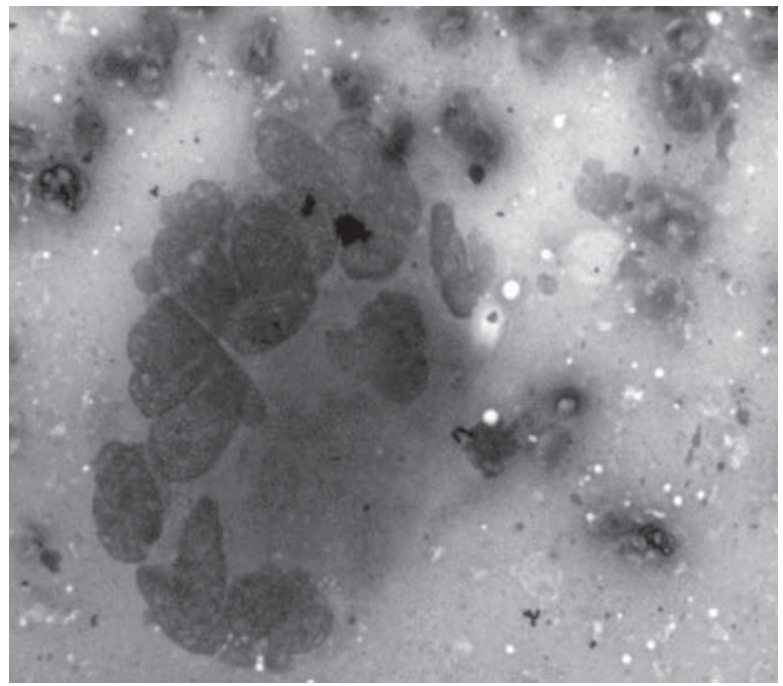

Fig. 5: Showing Granuloma with Clusters of Epitheloid Cells, Lymphocytes.

Ultrasonography of testis helped to arrive at a diagnosis. However, fine needle aspiration cytology of the lesion confirmed the diagnosis of testicular tuberculosis. The patient was started on four-drug antitubercular therapy with prednisolone. At present, 10 months after medication, the recurrence is not found. The conservative management gave satisfactory result. The repeat USG of testis and Mantoux were normal.

\section{Discussion}

Genitourinary Tuberculosis (TB) accounts for 20$73 \%$ of all cases of extra-pulmonary tuberculosis in the general population and epididymo-orchitis accounts 
for $22 \%$ of all cases of genitourinary tuberculosis ${ }^{4}$. Epididymal involvement was reported in $7 \%$ of all tuberculosis patients ${ }^{6}$.

The route of entry of the tuberculous bacillus into the scrotal sac structures is a controversial topic. Most believe that tuberculous epididymo-orchitis is secondary to direct retrograde spread from the urinary tract via reflux. However, tuberculous bacillus can also gain entry via the hematogeneous and lymphatic routes ${ }^{4}$

While it is agreed that tuberculous orchitis is secondary, this is by no means universal. Tuberculous orchitis may be the first and only presentation of genitourinary TB (GUTB),

as in our patient ${ }^{4}$. Carbal et $a l^{7}$ opined that higher frequency of isolated lesions in children as in our patient favoured the possibility of haematological spread of infection, while adults seem to develop tuberculous epididymo-orchitis as a result of direct spread from the urinary tract.

Tuberculous involvement of the epididymides and testes on USG can be of the following types: diffusely enlarged, heterogeneously hypoechoic; diffusely enlarged, homogenously hypoechoic; nodular enlarged, heterogeneously hypoechoic; or miliary ${ }^{8,9,10}$. Heterogeneity favours a tuberculous etiology ${ }^{9}$ as in our patient.

\section{Conclusion}

The case of a 14-year-old boy with tuberculous orchitis which shows no lesion in the epididymis is very rare and ours is the first reported case in the Nepalese literature. Tuberculous orchitis can be the sole presentation of genitourinary TB and hence FNAC of the testis should be performed with suspected testicular lesion even in the absence of clinical and laboratory markers of renal involvement. The response to antitubercular drugs given with prednisolone was rapid. This case emphasizes the importance of considering tuberculosis in differential diagnosis of scrotal and testicular enlargement in young children in an endemic area despite the absence of systemic, pulmonary and urinary manifestations ${ }^{11}$.

\section{Acknowledgement}

Sincere thanks to Dr. Anjan Shrestha (Pathologist) for kindly performing FNAC examination and confirming the tissue diagnosis of testicular tuberculosis and Dr. Ram Kumar Ghimire for USG. The author would like to acknowledge the child and the mother who kindly consented for publication and the authors are thankful for granting permission to publish the case report.

\section{References}

1. Hopewell PC. A clinical view of tuberculosis. Radiol Clin North Am 1995; 33:641-53.

2. Ross JC. Renal Tuberculosis. Br J Urol 1953; 25:277-315

3. Elkin M. Urogenital Tuberculosis. In: Pollack HM, editor. Clinical Urography. WB Saunders: Philadelphia; 1990. p. 1046.

4. Chattopadhyay A, Bhatnagar V, Agarwala S, Mitra DK. Genitourinary Tuberculosis in Pediatric Surgical Practice. J Pediatr Surg 1997; 32:12836.

5. Garbyal RS, Gupta P, Kumar S. Diagnosis of Isolated Tuberculous Orchitis by Fine-Needle Aspiration Cytology. Diagn Cytopathol 2006 Oct; 34(10): 698-700.

6. Reeve HR, Weinerth JL, Peterson LJ. Tuberculosis of Epididymis and Testicle presenting as Hydrocele. Urology 1974; 4:329-31.

7. Carbal DA, Johnson HW, Coleman GU, Nigro M, Speert DP. Tuberculous Epididymitis as a cause of Testicular Pseudomalignancy in two Young Children. Pediatr Infect Dis 1985; 4:59-62.

8. Kim SH, Pollack HM, Cho KS, Pollack MS, Han MC. Tuberculous Epididymitis and EpididymoOrchitis: Sonographic Findings. J Urol 1993; 150:81-4.

9. Drudi FM, Laghi A, Iannicelli E, Di Nardo R, Occhiato R, Poggi R, et al . Tubercular Epididymitis and Orchitis: US Patterns. Eur Radiol 1997; 7:1076-8.

10. Macmillan EW. The Blood Supply of the Epididymis in Man. Br J Urol 1954; 26:60-71.

11. Mbala L, Ilunga N, kadinekene K. 3-year-Old Boy with Tuberculous Epididymo-Orchitis. Trop Doct 1997 Jan; 27(1): 50-1. 